\title{
Determination of Heat Transfer Coefficient of Two Insulated Cotton Based on Wall Framing
}

\author{
Yao Lu ${ }^{\mathrm{a}}$, Wenbo Xie ${ }^{\mathrm{a}}$, Zheng Wang ${ }^{\mathrm{a} *}$ \\ ${ }^{a}$ College of Materials Science and Engineering, Nanjing Forestry University, Nanjing, Jiangsu 210037 China
}

\begin{abstract}
The heat preservation performance of the light wood frame construction wall directly affects the energy saving effect of the light wood frame construction. In order to strengthen the research of the thermal performance of the light wood structure wall and sandwich wall, in this paper, the heat transfer coefficient of glass-insulated cotton with two kinds of materials was measured in the exterior wall of the same light-weight wooden structure through field test method for heat transfer coefficient of construction so as to compare the test value and theory of the wall insulation coefficient Value, and preferably a thermal insulation cotton filling material. The conclusion shows that the wall filling material of guardian glass insulation performance is better than the Owens Corning Glass insulation cotton, and the former is adapted to the area of hot summer and cold winter and hot in summer and warm in winter, which is suitable for the hot summer and warm winter area. This paper is helpful to promote the energy saving optimization design of the wall structure of the light wood frame construction, and the engineering application value is high. Calculating the heat-conducting value of light wood structure wall, and the calculated values of the temperature of the constituent materials are comparable with the measured values actually, and the composite material theory can be used to predict the heat-conducting property of wood structure construction. The above is mentioned help to improve the level of on-site testing technology of heat-conducting, and provide a useful reference for the energy-saving insulation design work for light wood structure wall in our country, and this study has a high engineering application value.
\end{abstract}

Keywords: Wall Framing; Field Test Method; Insulation Cotton; Heat Transfer Coefficient; Energy - saving Insulation; Optimal Design

\section{INTRODUCTION}

Light wood structure building has created a comfortable living environment for people with its unique energy-saving insulation, thermal insulation, environmental friendliness, structural safety and earthquake resistance. It is more and more familiar in China ${ }^{[1-2]}$. Nowadays, due to the increasing demand for energy conservation and environmental protection for buildings, the insulation of building envelopes is also being improved and strengthened. In the building envelopes, the outer wall has the largest share ${ }^{[3-4]}$. Research shows that the building heat transfer through maintenance structure, its heat consumption accounts for $73 \%$ to $77 \%$ of the energy consumption of the entire building, of which the external wall consumes about $30 \%$ of heat, which also indicates that the external wall insulation is light wood structure residential energy saving. The most important link [5-6].

The light-weight wooden structure housing has attracted wide attention. At present, based on the

\footnotetext{
* Corresponding author: wangzheng63258@163.com
} 
introduction of foreign advanced construction technology and materials, the structural optimization design of the building and the physical and mechanical properties and classification of the plantation specification material and the wall structure materials have been Some research results, research work on energy-saving walls and composite wall heat transfer are being actively carried out ${ }^{[7-12]}$. In this paper, the on-site energy-saving detection technology is used to test the heat transfer coefficient of the same light-weight wooden structure house filled with two different insulation cottons based on steady-state conditions, and analyze the energy-saving wall insulation performance of existing light-wood houses. Put forward reasonable suggestions, and provide useful reference for the optimization design of energy-saving insulation of wall structure of light wood structure houses.

\section{MATERIALS AND METHODS}

\subsection{Testing object}

The test object is a light wood structure house wall built by Jiangsu Nanjing Senzhihu Construction Engineering Co., Ltd. The structure of the light wood structure wall is shown in Figure 1. The material of the wall column is SPF (Spruce: Spruce, Pine: Pine, Fir: Fir, Origin: Canada); the cover panel is oriented strand board (OSB); The filling material is R11 glass wool for Owens Corning in the United States, and $\mathrm{R} 13$ cotton wool ( $\mathrm{R}$ value cotton) $\mathrm{R} 13$. The parameters are shown in Table 1. The connecting parts include straight nails, code nails, and sealants and sealing strips., wall panel connection materials and other sealing materials.

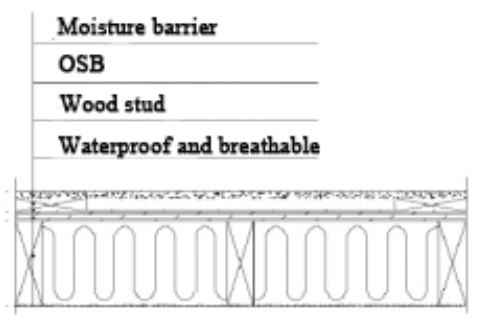

Fig. 1 light wood frame construction wall

Table 1.test materials and parameters

\begin{tabular}{cccc}
\hline material & length/mm & width $/ \mathrm{mm}$ & thickness $/ \mathrm{mm}$ \\
\hline SPF & 647 & 89 & 38 \\
OSB & 2440 & 1220 & 12 \\
Guardian & & 584 & \\
insulation & 2387 & & 70 \\
cotton & & & \\
Owens & & 1200 & \\
insulation & 2400 & &
\end{tabular}

\subsection{Test equipment}

1 set of HT-1 temperature heat flow inspection instrument, including: heat flow meter sensor, precision range $0 \sim 200 \mathrm{mV}$; Pt1000 model high precision waterproof temperature sensor, accuracy \pm $0.1^{\circ} \mathrm{C}$; data collector, by configuring different types of intelligent channel board, It can measure multiple semaphores such as voltage, current, thermocouple, 
thermal resistance and heat flow. Built-in large-capacity solid-state memory and animation editor (Flash), the data in the flash can be dumped to the computer through the $U$ disk, the built-in Flash capacity is $2 \mathrm{G}$, a total of 64 channels, the acquisition rate is $200 \mathrm{~ms}$ / per channel.

1 set of automatic temperature control hot box device. It has heating function, and sets the air temperature in the hot and cold box according to requirements, thus creating a one-dimensional steady heat transfer environment; and then detecting the heat transfer coefficient of the wall according to the heat flow meter method, which can effectively overcome the geographical and seasonal restrictions. The field test software is a building thermal data acquisition and processing system. After the on-site inspection, the heat transfer coefficient detection software of the enclosure structure will automatically screen the measured data that meets the requirements, calculate the heat transfer coefficient of the enclosure structure, and generate various curves, including: the temperature curve of indoor and outdoor air, and the temperature difference between indoor and outdoor air. Curve, inner and outer surface temperature curve of the envelope structure, temperature difference curve between the inner and outer surfaces of the envelope structure, heat flux density curve, etc.

\subsection{Test principle}

According to the provisions of Article 7.1.7 of the "Energy-saving Testing Standard for Residential Buildings " : the surface temperature of the high-temperature side of the enclosure shall be higher than $10^{\circ} \mathrm{C}$ above the low-temperature side, and shall not be equal to or lower than the surface temperature of the low-temperature side at any time during the inspection. In this test, the heat transfer coefficient of the wall is detected by the hot box-heat flow meter method, that is, based on the basic principle of the heat flow meter method, the hot box method is used to produce a basic stability for the on-site detection of the heat flow meter method, and the temperature difference between the tested parts is large. The test environment artificially guarantees the measured temperature difference on both sides of the tested enclosure structure and is used for on-site detection of the heat transfer coefficient of the envelope structure ${ }^{[13]}$. The on-site detection method is based on the heat flow meter method, and the entire room is used as a hot box, and the heat flow meter method is still used for the detection work. The schematic diagram of the test principle is shown in Figure 2.

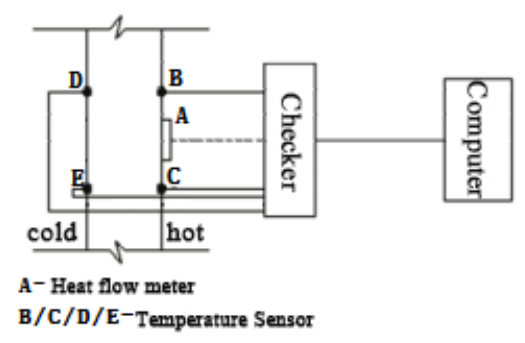

Fig.2 specimen 101 test spectrum of hemlock sawn timber

The heat flux through the enclosure was measured using a heat flow meter and the surface temperature on both sides of the enclosure was measured using a temperature sensor. According to the heat transfer formula, the heat transfer coefficient of the wall envelope structure is calculated. The measured thermal resistance $\mathrm{R}$ of the wall envelope structure to be tested is ${ }^{[14-18]}$ :

$$
R=\frac{\Delta t}{C V}
$$

Where: R-measured thermal resistance of the tested enclosure structure, $\mathrm{m} 2 \mathrm{k} / \mathrm{w}$;

$\Delta t$ - the difference between the hot and cold surface temperature of the tested enclosure, ${ }^{\circ} \mathrm{C}$;

C-heat flow sensor probe coefficient, take 8w/(m 2 v);

V-thermoelectric potential, $\mathrm{v}$.

The calculation formula of the heat transfer coefficient $\mathrm{K}$ of the tested enclosure is:

$$
K=\frac{1}{R_{i}+R_{o}+R}
$$

Where: $\mathrm{K}$ - the heat transfer coefficient of the enclosure structure to be tested, $\mathrm{w} /\left(\mathrm{m}^{2} \mathrm{k}\right)$;

$\mathrm{R}_{\mathrm{i}}$ - the heat transfer resistance of the inner surface of the 
tested enclosure, $\mathrm{m}^{2} \mathrm{k} / \mathrm{w}$;

$\mathrm{R}_{\mathrm{o}}$ - heat resistance of the outer surface of the enclosure to be tested, $\mathrm{m}^{2} \mathrm{k} / \mathrm{w}$.

\subsection{Test methods and procedures}

According to the "Inspection Standard for Thermal Performance of Civil Building Energy-saving Projects", the hot box-heat flow meter method is adopted. The heat flow meter and the thermocouple are used to detect the heat flow and the internal and external surface temperature of the wall to be tested, and the thermal resistance, heat transfer resistance and heat transfer coefficient of the wall are calculated to determine whether the building wall meets the energy-saving standard requirements.

(1) In order to improve the test accuracy of the results, the heat transfer coefficient of the residential north wall facing less affected by solar radiation is selected for on-site measurement. At the experimental site, the heat flow meter and the temperature sensor were respectively attached to the inner surface of the enclosure and in close contact with the surface.

(2) The specific arrangement of the sensor. According to the "Technical Regulations for On-site Detection of Heat Transfer Coefficient of Enclosure Structure" and "Inspection Standard for Thermal Performance of Civil Building Energy-Saving

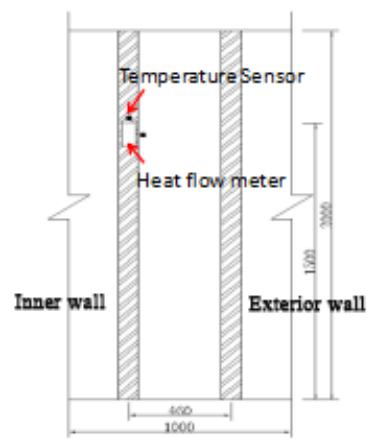

a.Internal sensor layout
Engineering", a heat flow sensor is installed, which is fixed on the inner surface of the outer wall, $1.5 \mathrm{~m}$ away from the ground; around the heat flow sensor Two surface temperature sensors were separately set and pasted with tin foil paper. The outer surface of the outer wall is not provided with a heat flow sensor. Two surface temperature sensors are required, and the center position of the inner wall heat flow sensor is matched and pasted with tin foil paper. The outdoor air temperature sensor is suspended in the air, $2.0 \mathrm{~m}$ from the ground, and is covered with aluminum foil. The indoor air temperature sensor is placed in the center of the room, $1.5 \mathrm{~m}$ from the ground. The paste diagram is shown in Figure 3.

(3) Place the hot furnace indoors during the test, so that the indoor temperature difference is $\geq 8{ }^{\circ} \mathrm{C}$, and the test time is $96 \mathrm{~h}$ after the heat transfer is stable. During the test, the heat flux density, the temperature of the inner and outer surfaces of the outer wall, and the temperature of the indoor and outdoor air were automatically recorded every 20 seconds.

(4) Replace the wall insulation cotton and repeat steps (1) and (2).

(5) Data recording and calculation of heat transfer coefficient.

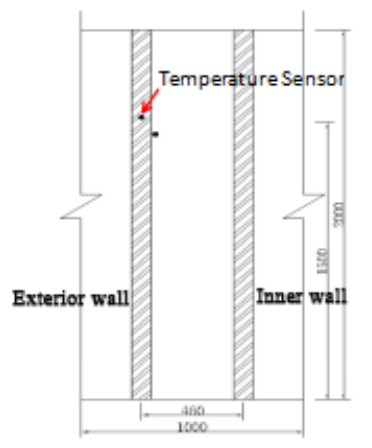

b.External sensor layout

Fig 3.Light wood frame construction wall sensor layout

From the test analysis data, the temperature

\section{RESULT ANALYSIS}

\subsection{Test results}

2.1.1 Guardian insulation cotton variation range of the inside and outside of the wall after the internal heating insulation cotton reaches the steady state is shown in Figure 4. The average ambient air temperature on the indoor side is $32.7^{\circ} \mathrm{C}$, the average outdoor air temperature is $21.06^{\circ} \mathrm{C}$, and the 
indoor and outdoor average temperature difference is $\quad 11.63{ }^{\circ} \mathrm{C}$.

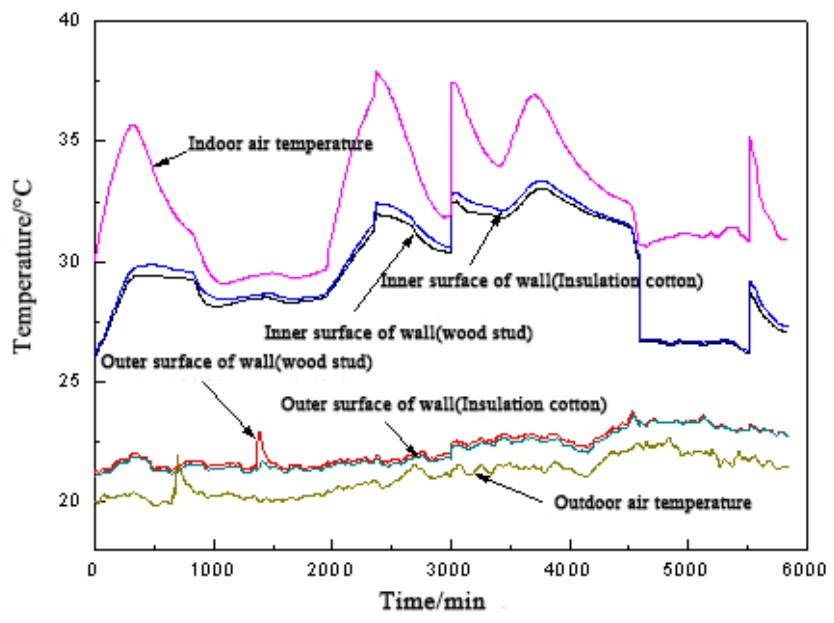

Fig 4 Temperature of each point of inner thermal insulation cotton with Guardian

\subsubsection{Owens insulation cotton}

From the test analysis data, the temperature variation range of the inside and outside of the wall after the Owens insulation cotton reaches the steady state is shown in Figure 5. The average air temperature inside the wall is $38.63{ }^{\circ} \mathrm{C}$, and the average outside air temperature is $27.52^{\circ} \mathrm{C}$. The indoor and outdoor temperature difference is $11.11^{\circ} \mathrm{C}$.

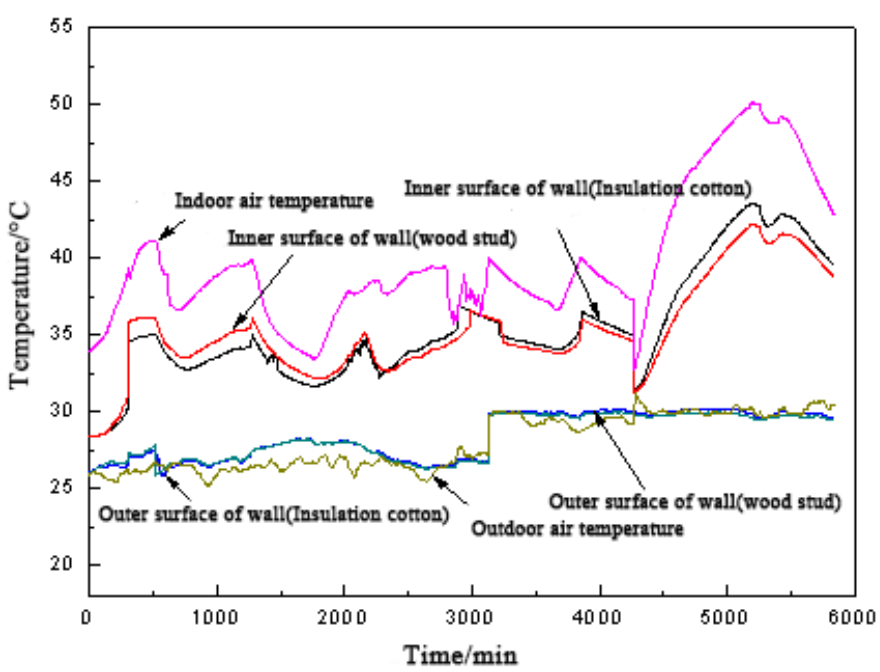

Fig 5 Temperature of each point of inner thermal insulation cotton with Owens

\subsection{Analysis of results}

\subsubsection{Thermal conductivity of materials}

The thermal parameters of the test materials are known by reference to GB 50176-93 "Code for
Design of Civil Buildings". The basic thermophysical parameters of the materials constituting the wall are shown in Table 2. 
Table 2. Basic thermal physical parameters of each layer material

\begin{tabular}{|c|c|c|c|}
\hline Parameter & $\begin{array}{c}\text { Thickness } \\
\mathrm{mm}\end{array}$ & $\begin{array}{c}\text { Thermal Conductivity } \\
\mathrm{w} \cdot \mathrm{m}^{-1} \cdot \mathrm{k}^{-1}\end{array}$ & $\begin{array}{c}\text { Thermal resistance } \\
\mathrm{m}^{2} \cdot \mathrm{k} \cdot \mathrm{w}^{-1}\end{array}$ \\
\hline OSB & 10 & 0.120 & 0.083 \\
\hline Chinese fir specification & 89 & 0.156 & 2.618 \\
\hline Guardian insulation & 89 & 0.034 & 2.022 \\
\hline Cwens insulation cotton & 89 & 0.044 & \\
\hline
\end{tabular}

\subsubsection{Calculation of theoretical value and test value of heat}

\section{transfer coefficient of wall envelope structure}

The theoretical value of the heat transfer coefficient of the building envelope is generally calculated based on the combination of the thermal conductivity of each material. For a one-dimensional layered structure, the heat transfer coefficient $\mathrm{K}$ is given by the following formula ${ }^{[19]}$ :

$$
K=\sum \frac{k_{i}}{\delta_{i}}
$$

Where ki represents the thermal conductivity of each layer of material and $\delta$ i represents the thickness of the material. Usually the heat transfer of the frame elements is neglected, but if the heat loss is accurately calculated, the frame structure in the wood wall must be considered. For the entire wall of the wood frame structure, the effective thermal resistance value or effective heat transfer coefficient is used to indicate the thermal insulation performance. The adjustment factor is generally determined by the area weighting method to determine the obstruction effect of the wall member on the heat flow. The thermal resistances Rs and $\mathrm{Rf}$ of the composite wall wall and the glass insulation material filling place are weighted according to the area, and the following formula is adopted. Calculate the total heat transfer coefficient of the wall, which is the effective heat transfer coefficient

$\mathrm{K}_{\text {effective }}$ is effective, describing the comprehensive heat transfer properties of composite structural walls composed of materials such as wood wall and insulation materials.

$$
K_{\text {effective }}=\frac{1}{R_{\mathrm{i}}+R_{\mathrm{o}}+R_{S}} \times \frac{F_{S}}{100}+\frac{1}{R_{i}+R_{o}+R_{\mathrm{f}}} \times \frac{F_{f}}{100}
$$

Where, $F_{f}$ - wood wall bones occupy the wall area value, take 9.89

Fs - the non-frame portion accounts for the wall area value, taking 90.1 ;

The heat resistance of the inner and outer surfaces is -0.11 $(\mathrm{m} 2 \mathrm{k} / \mathrm{w})$ and $0.04(\mathrm{~m} 2 \mathrm{k} / \mathrm{w})^{[20]}$.

Ks in Table 5 refers to the heat transfer coefficient of the composite wall at the wood keel, and Kf refers to the heat transfer coefficient of the composite wall at the filling of the insulation material ${ }^{[20]}$. Because there is a big difference in the thermal conductivity of the wood and the thermal insulation material, and there is no interior material inside the wooden structure, there is a certain error in the test results. In the entire frame wall composite structure, the heat transfer capability of the wood wall bone location is different from the filling position of the insulation material. The thermal conductivity of Chinese fir is about 4-5 times higher than that of glass wool, so Ks is always higher than $\mathrm{K}_{\mathrm{f}}$, both theoretically and practically.

The effective heat transfer coefficient test values of the two different insulation cotton fillers built into the same light wood structure wall are shown in Table 3, and the histogram comparison between the test value and the theoretical value is shown in Fig. 6. 
Table 3. Detection value and theoretical value of heat transfer coefficient

\begin{tabular}{|c|c|c|c|c|c|c|}
\hline \multirow{2}{*}{$\begin{array}{c}\text { Wall } \\
\text { Number }\end{array}$} & \multirow{2}{*}{$\begin{array}{l}\text { Wall filling } \\
\text { material }\end{array}$} & \multirow{2}{*}{$\begin{array}{l}\text { test value } \\
\mathrm{w} /\left(\mathrm{m}^{2} \cdot \mathrm{k}\right)\end{array}$} & \multicolumn{3}{|c|}{$\begin{array}{l}\text { Calculated value } \\
\qquad \mathrm{w} /\left(\mathrm{m}^{2} \cdot \mathrm{k}\right)\end{array}$} & \multirow{2}{*}{$\begin{array}{c}\text { Absolute } \\
\text { error }\end{array}$} \\
\hline & & & $\mathrm{K}_{\mathrm{f}}$ & $\mathrm{K}_{\mathrm{s}}$ & $\mathrm{K}_{\mathrm{e}}$ & \\
\hline Wall 1 & $\begin{array}{c}\text { Guardian } \\
\text { insulation } \\
\text { cotton }\end{array}$ & 0.657 & 1. 235 & 0.348 & 0.435 & 0.222 \\
\hline Wall 2 & $\begin{array}{c}\text { Owens } \\
\text { insulation } \\
\text { cotton }\end{array}$ & 0.832 & 1. 235 & 0.440 & 0.518 & 0.314 \\
\hline
\end{tabular}

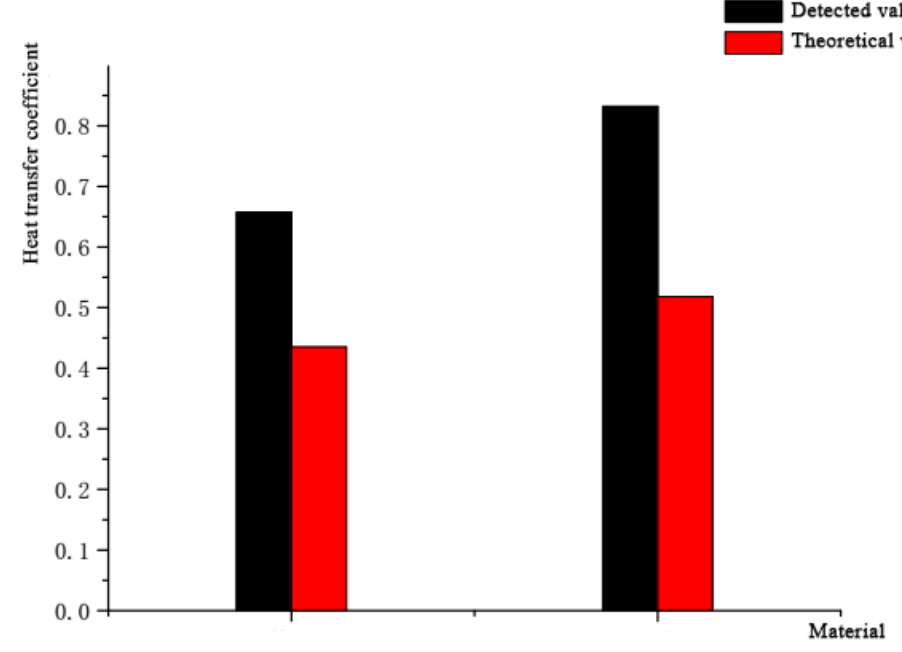

Fig 6. Comparison of the detection value and theoretical value of heat transfer coefficient

Obviously, the heat transfer coefficients of the light-weight wooden structure houses No.1 and No.2 on the site are $0.657 \mathrm{~W} /\left(\mathrm{m}^{2} \mathrm{~K}\right)$ and $0.832 \mathrm{~W} /\left(\mathrm{m}^{2} \mathrm{~K}\right)$, respectively, and the absolute error from the theoretical calculation is $0.222 \mathrm{~W} /\left(\mathrm{M}^{2} \mathrm{~K}\right)$ and $0.314 \mathrm{~W} /\left(\mathrm{m}^{2} \mathrm{~K}\right)$, the reason is that there is no gypsum board covered in the wall structure, and the wall is not flat, which causes the heat flow meter to have errors in collecting the heat flux density of the light wood structure wall. In addition, the uncovered gypsum board also produces an air layer, and the actual heat transfer of the air is not taken into account in the calculation, which is also the source of the error.

Table 4 lists the thermal grades and adaptation areas of the wood frame composite wall. They belong to the thermal grade IVt and Vt, respectively, and can be used in summer hot winter cold, hot summer warm winter, hot summer and warm winter, cold and cold regions $^{[21]}$. 
Table 4 thermal level and adaptation of the wall

\begin{tabular}{ccc}
\hline Thermal level & Heat transfer coefficient $\mathrm{w} /\left(\mathrm{m}^{2} \cdot \mathrm{k}\right)$ & area \\
\hline $\mathrm{I}_{\mathrm{t}}$ & $\leqslant 0.4$ & Severe Cold \\
$\mathrm{II} \mathrm{I}_{\mathrm{t}}$ & $\leqslant 0.5$ & Severe Cold、 Cold \\
$\mathrm{III}_{\mathrm{t}}$ & $\leqslant 0.6$ & Cold $、$ \\
$\mathrm{IV}_{\mathrm{t}}$ & $\leqslant 1.0$ & hot-summer and cold-winter \\
& & hot-summer and cold-winter hot summer \\
$\mathrm{V}_{\mathrm{t}}$ & $\leqslant 1.2$ & and warm winter
\end{tabular}

2.2.3 Analysis of the influence of thermal bridge on wall heat transfer

The light-weight wood structure building composite structure wall absorbs heat and releases heat differently inside and outside the body. The assembly of the wall body is usually fixedly connected by metal connectors such as straight nails and code nails. During the wall construction process, the reserved joint between the cladding panels (oriented strand board), the metal joints used for connection and fixing, the structural installation gaps, etc., will increase the local heat transfer of the wall and reduce the average thermal resistance of the wall. In particular, the influence of metal joints on the heat transfer of the wall is also the main source of error between the test results and the theoretical calculation values. Metal connectors are widely used in light wood construction, and the thermal conductivity of iron is $80 \mathrm{w} /(\mathrm{m} 2 \mathrm{k})$, which is much larger than the thermal conductivity of fir $0.156 \mathrm{w} /(\mathrm{m} 2 \mathrm{k})$, that is, the application of metal connectors increases the wall. The heat transfer of the body increases the energy consumption of the building and reduces the energy-saving and heat preservation effect.

\section{CONCLUSIONS}

3.1 The same light-weight wooden structure building exterior wall structure is built with two different glass insulation materials, and the structural heat transfer is measured on site. The test results show that the wall body filling material is the insulation structure of the wall structure of American Guardian glass insulation cotton. The wall filling structure is better than the wall material of Owens Corning glass insulation cotton.

3.2 The numerical calculation of heat transfer on the light wood structure wall, the calculated values of the temperature of each component material have the same contrastability with the test value, the test data is reliable, and the concrete insulation energy-saving requirements of the building wall can be carried out according to the composite material theory. design.

3.3 Light-duty wooden structure wall has double insulation structure of filling between wooden wall bone and outer cladding surface. The temperature difference of the material unit intuitively reflects that the thermal insulation material and the increased thickness of the wooden wall bone can reduce the heat loss of the frame position, and The thermal insulation effect of the external thermal insulation material is obvious. The heat transfer of the wood frame part of the light wood structure wall is $2-3$ times that of the non-wood frame part. The heat transfer of the wood keel is greater than that of the heat insulation cotton, 
so the area and thickness of the heat preservation material are appropriately increased, and the frame material with small thermal conductivity is used and filled. Materials that reduce heat transfer and are designed to achieve the best energy savings through specific construction.

3.4 According to the comparison of thermal performance, the light wood structure building wall filled with American Guardian glass insulation cotton meets the thermal grade IVt, suitable for summer hot winter cold and summer hot winter warm area, Owens Corning glass insulation cotton filled light type The wooden structure building wall meets the thermal grade $\mathrm{Vt}$ and is suitable for the hot summer and warm winter areas.

3.5 Metal joints widely used in light wood construction are one of the building thermal bridges, which will greatly increase the heat transfer of the wall and affect the insulation of the building. Therefore, in the design and construction process, it is recommended to reduce the nail distance, use the nail with relatively small thermal conductivity, or use some new composite materials to replace the connection to ensure better heat preservation and better insulation effect.

\section{REFERENCES}

1. Guo Wei, Fei Benhua, Chen Enling, et al. Analysis of the development status of China's wood structure construction industry[J].China Wood Industry, 2002,23(2):19-22.

2. Xie Qifang,Lu Xilin,Xiong Haibei.Structural Characteristics and Improvement of Light-weight Wooden Structure Houses[J].Journal of Building Structures(Supplement 2), 2010,45(s2):350-354.

3. Wang Zhen,Zhang Yong-yi,Chen You-lu,et al.Energy-saving test evaluation of energy-saving building envelope structure[J].Journal of Daqing Petroleum Institute, 2001,25(1):101-103

4. Zhang Zeping,Li Zhu,Dong Yanli.Development Status and Prospect of Building Insulation and Energy Saving Wall[J].Engineering
Mechanics,2007,24(Supplement 2):121-128.

5. Xi Jia,Zhao Rongjun,Fei Benhua, et al.Introduction to the composition of wood structure building wall[J].Forest industry,2010,(2):45-47.

6. Tian Binshou, Yang Yongheng, Meng Yuan, et al. On-site detection of building heat transfer coefficient using heat flow meter[J]. Thermal Insulation Materials \& Building Energy Conservation, 2004, (8): 59-61.

7. Zhu Qingyi,Zhao Fade,Zhao Jinping.Research Status and Development of Exterior Wall Insulation Materials $[\mathrm{J}]$ N New Building Materials,2012,(06):12-16.

8. Gu Tianshu,Xie Lianyu,Chen Ge.Building Energy Saving and Wall Insulation[J].Engineering Mechanics,2006,23(Supplement 2):167-184.

9. Hu Zhenjun,Su Zhenguo, Yang Jinlong.Research and Application of Exterior Insulation Materials for Building Exterior Walls[J].Materials Review,2012,26(Album 20):290-294.

10. Wang Z., Li L., Gong M. Measurement of dynamic modulus of elasticity and damping ratio of wood-based composites using the cantilever beam vibration technique[J].Construction and Building Materials,2012, 28(1):831-834.

11. Hadia A, Mustafa G, Hamid Z, et al. Evaluation of the thermal and structural performance of potential energy efficient wall systems for mid-rise wood-frame buildings [J]. Energy and Buildings.2014,82:416-427.

12. Zoltan P, Perry N P, Sandor M, et al. Modeling the hygrothermal performance of selected North American and comparable European wood-frame house walls [J]. Energy and Buildings.2012,49: 142 $-147$.

13. Wang Xiaohuan,Fei Benhua,Zhou Haibin, et al.Steady-state heat transfer properties of domestic light-weight wooden structural wall[J]. Civil 
Engineering and Environmental Engineering, 2010, 32(4): 76-79.

14. Wang Xiaohuan,Fei Benhua,Wang

Yongbing.Experimental Study on Thermal

Insulation Performance of Wood Frame Exterior Wall[J].Wood

Processing

Machinery,2013,(6):11-15.

15. Wang Zhiqiang, Zhou Tongjian, Cao Fuliang, et al. Heat transfer performance of ginkgo wood hollow particleboard composite wall[J].Wood Industry,2010,24(5):5-7.

16. Zhou Tongjian, Zhang Haiyang, Wang Zhiqiang, et al. Calculation of thermal insulation performance of ginkgo wood hollow particleboard composite wall [J]. Building Energy Conservation, 2012, (11): 42-44.

17. 17.Xu H., Li S. Saving Strategy and Simulation Analysis of Green Log Walls in Severe Cold Area[J]. Journal of Harbin Institute of Technology (New Series),2014,21(5):46-51.

18. Wu H., Zhang M, Lu Q., et al. The Heat Transfer Coefficients of the Heating Surface of $300 \mathrm{MWe}$ CFB Boile r[J]. Journal of Thermal Science, 2012, 21(4): 368-376.

19. $\mathrm{Yu}$ Lihang.Calculation and Analysis of Average Heat Transfer Coefficient of Exterior Wall[J].Insulation Materials and Building Energy Conservation,2003,(11):54-57.

20. Zhang Hualing,Zhang Minfei.The Thermal Calculation Method and Air Conditioning Load Analysis of Lightweight Wood Structure Exterior Wall[J].Journal of Tongji University(Natural Science),2012,40(5):735-739.

21. Wang Xiaohuan, Fei Benhua, Ren Haiqing, et al. Numerical calculation and experimental study on heat transfer of light wood structure wall[J]. Journal of Building Materials, 2011, 14(4): 517-522. 